\title{
Differences in Giving of Mc Kenzie Exercise and Core Stability Exercise toward Functional Activity of Patients with Lower Back Pain in GrandMed Hospital Lubuk Pakam
}

\author{
Tati Murni Karokaro, Melisa Queen Hutabarat2)
}

\author{
Institut Kesehatan Medistra Lubuk Pakam \\ Fakultas Keperawatan dan Fisioterapi Program Studi Ilmu Keperawatan \\ Jl. Sudirman No 38 Lubuk Pakam, Kab. Deli Serdang SUMUT \\ tatikarokaro612sp@gmail.com
}

\begin{abstract}
In fulfillment of these needs sometimes human forget to maintain their health, good attitude so that the position in work is not ergonomic which can lead to problems when carrying out activities. Lower back pain is a clinical symptom that is characterized by pain or a discomfort feeling in lower back area. In the United States, the incidence of lower back pain region in the past one year is 15\% -20\%. This study aims to see whether there were differences in giving of Mc Kenzie and Core Stability Exercise toward Functional Activity of Patients with Lower Back Pain. This study is quasi experiment with a sample of patients with lower back pain, with purposive sampling technique. The results obtained are $p$-value $a<(0,000<0,05)$, it means that there is a difference in giving of Mc Kenzie Exercise toward the increase of Functional Activity of Patients with Lower Back Pain, that uses body movements that is directed to extension, to provide strengthening and reflecting on the extensor and flexor muscles of the lumbar joint, while the Core Stability Exercise has the ability to regulate the position and movement in the central region of the body, and it can be concluded that there is differences in Giving of Mc Kenzie Exercise toward the increase of Functional Activity of Patients with Lower Back Pain. It is recommended for patients who experience lower back pain so that keep always repeat the exercises that suggested by physiotherapist, for further research so that choose more samples.
\end{abstract}

Keywords: Mc Kenzie Exercise, Core Stability Exercise, Functional Activity, Low Back Pain

\section{Pendahuluan}

Tubuh yang sehat tidak terlepas dari terpenuhinya kebutuhan sehari hari baik secara fisiologis, aman dan nyaman, cinta dan memiliki, harga diri dan aktualisasi diri. Sebagai kebutuhan yang paling dasar yaitu fisiologi maka setiap manusia harus lebih giat dan semangat untuk memenuhinya agar dapat beraktifitas dengan baik. Dalam pemenuhan kebutuhan tersebut terkadang manusia sampai lupa untuk menjaga kesehatannya seperti lupa makan, istirahat, lupa menjaga sikap yang baik dan benar sehingga posisi dalam bekerja tidaklah ergonomis yang akan dapat mengakibatkan timbulnya masalah bahkan sampai terjadi kecelakaan pada saat melakukan aktifitas tersebut. Kecelakaan kerja yang paling sering terjadi adalah nyeri pada daerah punggung bawah (NBP) (Perdani, 2014).

Nyeri punggung bawah merupakan suatu gejala klinik yang ditandai dengan adanya rasa nyeri atau perasaan yang kurang nyaman di daerah punggung bawah, namun nyeri yang dirasakan tersebut dapat hilang dengan sendirinya tanpa mendapatkan perawatan. Keluhan nyeri yang hilang timbul dapat mengakibatkan resiko penurunan dari fungsi kerja otot-otot dan tulang belakang untuk itu pasien 
yang mengalami nyeri punggung bawah yang tidak melakukan latihan khusus akan memiliki resiko 12 kali mengalami kekambuhan dalam kurun waktu tiga tahun, otot yang mengalami penurunan fungsi dalam kurun waktu yang lama dapat mengakibatkan penurunan kekuatan otot sehingga terjadi penurunan aktifitas sehari-hari pasien (Hills, 2016).

Penanganan yang dilakukan untuk mengurangi rasa yeri pada aerah punggung bawah maka dapat dilakukan dengan cara Mc. Kenzie Exercise dan Core Stability Exercise. Mc. Kenzie Exercise adalah suatu tehnik yang dilakukan oleh penderita nyeri pinggung bawah dengan menggerakkan anggota tubuh ke arah extensi dengan menggunakan penguatan serta peregangan otot-otot extensor dan flexor dengan tujuan untuk mengurangi rasa nyeri. Tujuan latihan ini adalah untuk memperbaiki postur untuk menurangi hiperlorosis lumbal. Sedangkan Core stability merupakan latihan yang dilakukan untuk aktifitas yang sinergis pada otototot bagian dalam atau otot-otot inti yang dapat mengakibatkan timbulnya rasa nyeri pada daerah punggung bawah, dan latihan ini juga melibatkan keseimbangan didalam tubuh pasien yang akan mengikuti latihan (Brandon dan Raphael, 2013, Quinn, 2013 dan Mc Kenzie, 2011)

Di Negara maju Seperti di Negara Amerika Serikat angka kejadian yang mengalami nyeri pada daerah punggung bawah dalam kurun waktu satu tahun terakhir adalah 15\%-20\%, sedangkan angka kejadian berdasarkan kunjungan pasien ke poliklinik dan dokter sekitar 14,3\%. Di Afrika dari hasil penelitian yang dilakukan didapatkan data bahwa remaja mengalami nyeri punggung bawah sekitar 33\% sedangkan orang dewasa sekitar $50 \%$, dan hasil penelitian yang dilakukan di Rumah Sakit Pusat Angkatan Darat Gatot Subroto Jakarta, angka kejadian nyeri punggung bawah didapat $24,4 \%$ dan rasa nyeri punggung bawah ini akan bertambah sesuai dengan penambahan usia masing-masing pasien yang mengalami nyerinya (Meliawan, 2013 \& Mahadewa, 2014).

Dari hasil studi pendahuluan yang dilakukan di poli fisioterapi rumah sakit Grandmed Lubuk Pakam maka didapat data pasien yang mengalami keluhan nyeri daerah punggung bawah sekitar 1000 kasus pertahun. Tujuan dalam penelitian ini adalah untuk melihat apakah ada perbedaan dalam pemberian Mc Kenzie dan Core Stability terhadap aktifitas fungsional pada pasien yang mengalami nyeri punggung bawah di rumah sakit Grandmed lubuk pakam

\section{METODE}

Penelitian ini dilakukan secara Quasi experiment, yang bertujuan untuk membuktikan Perbedaan Pemberian Mc Kenzie Exercise dan Core Stability Exercise terhadap Aktifitas Fungsional pada Pasien Nyeri Punggung Bawah di Rumah Sakit GrandMed Lubuk Pakam. Sampel dalam penelitian ini adalah pasien yang mengalami Nyeri punggung bawah yang telah melewati masa akut, yaitu minimal lebih dari 10 hari, tidak mengalami kelainan neurologis, usia sampel 25-50 tahun. Teknik pengambilan sampel yang digunakan adalah Purposive Sampling.

\section{HASIL}

Tabel 4.1

Karakteristik Responden Berdasarkan Usia pada Kelompok Mc Kenzie Exercise dan Kelompok Core Stability Exercise di Rumah Sakit GrandMed Lubuk Pakam 
Jurnal Keperawatan \& Fisioterapi (JKF)

Vol. 1 No.1 Edisi Mei-Oktober 2018

http://ejournal.medistra.ac.id/index.php/JKF

Received: 02 Agustus 2018 :: Revised: 08 September 2018:: Accepted: 10 Oktober 2018

\begin{tabular}{llccc}
\hline eristik & \multicolumn{2}{c}{ MKE } & \multicolumn{2}{c}{ CSE } \\
\cline { 2 - 5 } Respo & $\begin{array}{l}\text { Frek } \\
\text { nden }\end{array}$ & $\begin{array}{l}\text { uen } \\
\text { si }\end{array}$ & & $\begin{array}{l}\text { Fre } \\
\text { kue } \\
\text { nsi }\end{array}$ \\
Usia : & & & & \\
$25-34$ & 7 & $25,0 \%$ & 9 & $32,1 \%$ \\
$35-44$ & 5 & $17,9 \%$ & 4 & $14,3 \%$ \\
$45-60$ & 2 & $7,1 \%$ & 1 & $3,6 \%$ \\
Total & $\mathbf{1 4}$ & $\mathbf{1 0 0} \%$ & $\mathbf{1 4}$ & $\mathbf{1 0 0 \%}$ \\
\hline \multicolumn{3}{c}{ Berdasarkan } & \multicolumn{3}{c}{ Tabel }
\end{tabular}

menunjukan bahwa jumlah responden untuk mengikuti latihan $m c$ kenzie yaitu 7 orang sedangkan yang mengikuti latihan core stability 9 orang pada usia 25 - 34, pada usia 35-44 tahun 5 orang mengikuti latihan $m c$ kenzie dan 4 orang mengikuti latihan core stability, pada usia 45-60 tahun 2 orang mengikuti latihan mc kenzie dan 1 orang mengikuti latihan core stability.

Tabel 4.2

Distribusi Responden Berdasarkan Karakteristik Pekerjaan pada Kelompok Mc Kenzie Exercise dan Kelompok Core Stability Exercise Di Rumah Sakit Grandmed

\begin{tabular}{|c|c|c|}
\hline & $\begin{array}{c}\text { Kelompok } \\
\text { MKE }\end{array}$ & Kelompok CSE \\
\hline Responden & $\begin{array}{c}\text { Fre } \\
\text { kue } \\
\text { nsi }\end{array}$ & $\begin{array}{l}\text { Frek } \\
\text { uensi }\end{array}$ \\
\hline
\end{tabular}

Pekerjaan :

\begin{tabular}{lllll} 
IRT & 6 & $21,4 \%$ & 5 & $17,9 \%$ \\
Pegawai & 3 & $10,7 \%$ & 4 & $14,3 \%$ \\
$\begin{array}{l}\text { Karyawan } \\
\text { Swasta }\end{array}$ & 5 & $17,9 \%$ & 5 & $17,9 \%$ \\
Total & $\mathbf{1 4}$ & $\mathbf{1 0 0} \%$ & $\mathbf{1 4}$ & $\mathbf{1 0 0} \%$ \\
\hline
\end{tabular}

$\begin{array}{cccc}14 & 100 \% & 14 & 100 \%\end{array}$
jumlah responden berdasarkan pekerjaan yaitu, IRT sebanyak 6 orang pada kelompok Mc Kenzie Exercise dan 5 orang kelompok Core Stability Exercise. Pegawai sebanyak 3 orang pada kelompok Mc Kenzie Exercise dan 4 orang, pada kelompok Core Stability Exercise. Karyawan Swasta 5 orang pada kelompok Mc Kenzie Exercise dan 5 orang pada kelompok Core Stability Exercise.

Tabel 4.3
Distribusi Responden Berdasarkan Karakteristik Indeks Massa Tubuh pada Kelompok Mc Kenzie Exercise dan Kelompok Core Stability Exercise Di Rumah Sakit Grandmed

\begin{tabular}{|c|c|c|c|c|}
\hline \multirow{2}{*}{$\begin{array}{l}\text { Karekterist } \\
\text { ik } \\
\text { Responden }\end{array}$} & \multicolumn{2}{|c|}{$\begin{array}{l}\text { Kelompok } \\
\text { MKE }\end{array}$} & \multicolumn{2}{|c|}{$\begin{array}{l}\text { Kelompok } \\
\text { CSE }\end{array}$} \\
\hline & $\begin{array}{l}\text { Fre } \\
\text { kue } \\
\text { nsi }\end{array}$ & $\%$ & $\begin{array}{l}\text { Fre } \\
\text { kue } \\
\text { nsi }\end{array}$ & $\%$ \\
\hline$>25$ & 6 & $21,4 \%$ & 8 & $28,6 \%$ \\
\hline$<25$ & 8 & $28,6 \%$ & 6 & $21,4 \%$ \\
\hline Total & 14 & $100 \%$ & 14 & $100 \%$ \\
\hline
\end{tabular}
jumlah responden berdasarkan Indeks Massa Tubuh (IMT) yaitu, Indeks Massa Tubuh > 25 pada kelompok Mc Kenzie Exercise sebanyak 6 orang dan 8 orang pada kelompok Core Stability Exercise, sedangkan indek massa tubuh $<25$ pada kelompok Mc Kenzie Exercise sebanyak 8 orang dan 6 orang pada kelompok Core Stability Exercise.

Tabel 4.4

Nilai Aktifitas Fungsional sebelum dan sesudah di berikan Mc Kenzie Exercise

\begin{tabular}{lcc}
\hline $\begin{array}{c}\text { Aktifitas } \\
\text { Fungsional }\end{array}$ & Mean & $\begin{array}{c}\text { Std } \\
\text { Deviation }\end{array}$ \\
\hline Sebelum & 33,93 & 5,045 \\
Sesudah & 27,36 & 5,569 \\
\hline \multicolumn{2}{c}{ Berdasarkan table } & 4.4 dapat
\end{tabular}

dilihat ada selisih hasil mean yaitu mean sebelum 33,93 dengan SD 5,045 dan hasil mean sesudah Mc Kenzie Exercise 27,36 dengan SD 5,569.

Tabel 4.5

Nilai Aktifitas Fungsional sebelum dan sesudah di berikan Core Stability Exercise

\begin{tabular}{ccc}
\hline $\begin{array}{c}\text { Aktifitas } \\
\text { Fungsional }\end{array}$ & Mean & $\begin{array}{c}\text { Std } \\
\text { Deviation }\end{array}$ \\
\hline Sebelum & 33,14 & 5,776 \\
Sesudah & 25,71 & 6,354 \\
\hline \multicolumn{2}{c}{ Berdasarkan table } & 4.5
\end{tabular}

dilihat ada selisih hasil mean sebelum, 
Jurnal Keperawatan \& Fisioterapi (JKF)

Vol. 1 No.1 Edisi Mei-Oktober 2018

http://ejournal.medistra.ac.id/index.php/JKF

Received: 02 Agustus 2018 :: Revised: 08 September 2018:: Accepted: 10 Oktober 2018

33,14 dengan SD 5,776 sedangkan hasil mean sesudah 25,71 dengan SD 6,354 .

Tabel 4.6

Uji Normalitas Data Responden Menurut Nilai Selisih Aktifitas Fungsional pada Pelakuan McKenzie Exercise dan Core Stability Exercise di Rumah Sakit GrandMed

\begin{tabular}{|c|c|c|c|c|}
\hline \multirow{2}{*}{$\begin{array}{l}\text { Nilai } \\
\text { Selisih } \\
\text { Aktifitas } \\
\text { Fungsional }\end{array}$} & \multicolumn{2}{|c|}{$\begin{array}{c}\text { Kolmogorov- } \\
\text { Simirnov }\end{array}$} & \multicolumn{2}{|c|}{ Shapiro-Wilk } \\
\hline & $\begin{array}{c}\text { Freku } \\
\text { ensi }\end{array}$ & $\mathbf{P}$ & $\begin{array}{c}\text { Frekue } \\
\text { nsi }\end{array}$ & $\mathbf{P}$ \\
\hline Selisih MKE & 14 & 0,200 & 14 & 0,118 \\
\hline Selisih CSE & 14 & 0,200 & 14 & 0,241 \\
\hline
\end{tabular}

Berdasarkan hasil uji normalitas data pada pengukuran aktifitas fungsional dengan menggunakan skala Oswastry Disability Indeks (ODI) maka diperoleh data dengan nilai Selisih MKE $P=0,0118$ dan selisih CSE $P=0,241$. Dimana, bila nilai $\mathrm{P}>0,05$ maka data berdistribusi normal

Tabel 4.7

Hasil Analisis Paired $\mathrm{T}$ Test Pada Kelompok Mc Kenzie Exercise

\begin{tabular}{lcccc}
\multicolumn{1}{c}{$\begin{array}{c}\text { Aktifitas } \\
\text { Fungsional }\end{array}$} & Mean & $\begin{array}{c}\text { Std } \\
\text { Deviation }\end{array}$ & T & $\begin{array}{c}\boldsymbol{p} \text { - } \\
\text { value }\end{array}$ \\
\hline $\begin{array}{l}\text { Sebelum } \\
\text { MKE - }\end{array}$ & 6,571 & 1,869 & 13,153 & 0,000 \\
$\begin{array}{l}\text { sesudah } \\
\text { MKE }\end{array}$ & & & & \\
\hline
\end{tabular}

Dari tabel 4.7 Hasil Uji statistik didapatkan nilai $p=0,000 \leq a=0,05$ maka dapat disimpulkan bahwa terdapat Pengaruh mc kenzie exercise terhadap peningkatan aktivitas fungsional pada pasien nyeri punggung bawah mekanik di rumah sakit Grandmed

\section{Tabel 4.8}

Selisih intesitas Nilai Aktifitas Fungsional sebelum - sesudah pemberian Kelompok Core Stability Exercise

\begin{tabular}{lcccc}
\hline $\begin{array}{l}\text { Aktifitas } \\
\text { Fungsional }\end{array}$ & Mean & $\begin{array}{c}\text { Std } \\
\text { Deviation }\end{array}$ & t & $\begin{array}{c}\boldsymbol{p}- \\
\text { value }\end{array}$ \\
\hline
\end{tabular}

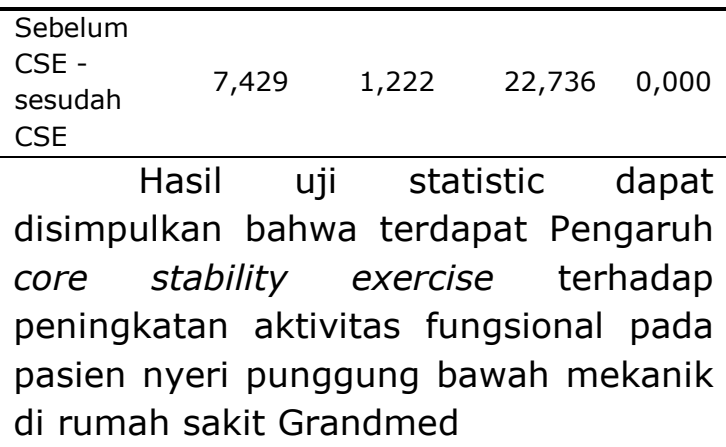
peningkatan aktivitas fungsional pada pasien nyeri punggung bawah mekanik di rumah sakit Grandmed

Tabel 4.9

Selisih Rerata Nilai Aktifitas Fungsional pada Kelompok Mc Kenzie Exercise dengan Kelompok Core Stability Exercise

\begin{tabular}{|c|c|c|c|c|}
\hline & $\mathbf{T}$ & $\begin{array}{c}\text { Sig(2 } \\
- \\
\text { tailed }\end{array}$ & $\begin{array}{c}\text { Mean } \\
\text { Differenc } \\
\text { e }\end{array}$ & $\begin{array}{c}\text { Std Error } \\
\text { Differenc } \\
\text { e }\end{array}$ \\
\hline $\begin{array}{l}\text { Equal } \\
\text { variance }\end{array}$ & $\begin{array}{c}- \\
1,43\end{array}$ & 0,001 & $-0,857$ & 0,597 \\
\hline $\begin{array}{l}\text { s } \\
\text { assume } \\
\text { d }\end{array}$ & 6 & & & \\
\hline $\begin{array}{l}\text { Equal } \\
\text { variance } \\
\text { s not } \\
\text { assume } \\
\text { d }\end{array}$ & $\begin{array}{c}- \\
1,43 \\
6\end{array}$ & 0,001 & $-0,857$ & 0,597 \\
\hline
\end{tabular}
value $\alpha<(0,000<0,05)$ maka dapat disimpulkan yaitu : "Ada Perbedaan Pemberian Mc kenzie Exercise terhadap Peningkatan Aktivitas Fungsional pada Pasien Nyeri Punggung Bawah Mekanik di Rumah Sakit Grandmed

\section{PEMBAHASAN}

Karakteristik responden berdasarkan umur, pekerjaan, dan nilai IMT

Angka kejadian NBP setiap tahun di negara Amerika Serikat didapatkan 
data bahwa 15\%-45\% dan angka kejadian tersebut terbanyak ditemukan pada usia 35-55 tahun. NPB dapat dialami sejak remaja atau dewasa, yaitu usia 25 hingga 55 tahun, Rentang umur dapat menunjukkan bahwa semua yang mengalami NBP termasuk pada usia yang produktif. NBP yang paling banyak ditemukan adalah NBP mekanik dimana sebagian besar terjadi pada bekerja sebagai ibu rumah tangga. Hal ini sesuai dengan penelitian lainnya bahwa NBP dapat disebabkan karena bekerja dengan aktivitas yang lebih berat dan posisi yang kurang baik saat melakukan pekerjaan. Hal ini dapat terjadi dikarenakan terjadinya penyumbatan pada aliran darah yang megakibatkan terjadinya kekurangan oksigen dan glukosa dari darah. Indek massa tubuh Tubuh $>25$ atau overweight akan lebih berisiko 5 kali lipat mengalami NBP dibandingkan dengan berat badan normal maupun ideal. Ketika berat badan bertambah, maka beban pada tulang belakang akan bertambah dan menerima tekanan yang semakin berat yang dapat mengakibatkan kerusakan pada struktur tulang belakang khususnya pada daerah lumbal, ((Turder \& Koes (2001) dan Kisner (2014)).

Uji beda pengaruh peningkatan aktivitas fungsional kelompok Mc Kenzie Exercise

Mc Kenzie Exercise latihan yang menggunakan gerakan badan yang diarahkan kearah ekstensi yang gunanya untuk memberikan penguatan dan perengangan pada otot - otot ekstensor dan fleksor sendi lumbal dan sakralis untuk mengurangi rasa nyeri. Stretching yang dilakukan pada dalam latihan Mc Kenzie adalah guna untuk mencegah terjadinya perlengketan jaringan otot dan mencegah terjadinya inflamasi di daerah rongga persendian sehingga pergerakan pada daerah gerak sendi dapat terpelihara dengan baik, tindakan ini dapat diberikan kepada pasien dalam keadaan rileks untuk lebih memberikan efek dalam mengurangi rasa nyeri pada daerah punggung bawah. Gerakan - gerakan yang diajarkan kepada pasien adalah gerakan yang sederhana yang dapat memberikan rangsangan kepada propioseptor, dimana fungsi dari propioseptor adalah untuk mengaktifkan serabut efferent yang mengakibatkan tertutupnya spinal gate. pada latihan Mc Kenzie Exercise lebih cenderung kearah pengistirahatan punggung Kisner (2014)

\section{Uji beda pengaruh peningkatan aktivitas fungsional kelompok Core Stability Exercise}

Core Stability Exercise memiliki kemampuan dalam mengatur posisi dan pergerakan pada daerah pusat tubuh, karena yang menjadi target utama latihan ini adalah otot-otot perut yang berhubungan langsung dengan tulang belakang, panggul, dan bahu. Manfaat dari CSE adalah menjaga keseimbangan fungsi punggung bawah agar tetap stabil dan dapat bekerja sesuai dengan yang dilakukan oleh pasien serta mencegah terjadinya cedera terutama ketika pasien meningkatkan aktivitas. CSE dapat mengakibatkan keseimbangan otot-otot perut dan tulang belakang yang akan membentuk aktifitas lebih baik karena terjadi koaktivitas otot yang dapat mengontrol pergerakan berat badan seperti melangkah maupun meraih ((Brandon \& Raphael, (2013), (Meliala dan Pinzon, 2014)).

Uji beda setelah perlakuan Mc Kenzie Exercise dan Core Stability Exercise di Rumah Sakit Grandmed Lubuk Pakam

Hasil Uji statistic t-test independent didapat $t$ hitung $-1,436$ dengan $p$-value $\alpha<(0,001<0,05)$, mean selisih Pre-Post kelompok Mc 
Kenzie Exercise dengan mean selisih Pre-Post kelompok Core Stability Exercise, Sehingga hipotesa pada penelitian ini di terima yaitu : "Ada Perbedaan pemberian Mc Kenzie Exercise dan Core Stability Exercise terhadap aktifitas Fungsional pada Penderita nyeri Punggung Bawah

\section{KESIMPULAN}

a. responden untuk mengikuti latihan $m c$ kenzie yaitu 7 orang sedangkan yang mengikuti latihan core stability 9 orang pada usia 25 - 34, pada usia 35-44 tahun 5 orang mengikuti latihan $m c$ kenzie dan 4 orang mengikuti latihan core stability, pada usia 45-60 tahun 2 orang mengikuti latihan $m c$ kenzie dan 1 orang mengikuti latihan core stability.

b. Hasil mean yaitu mean sebelum 33,93 dengan SD 5,045 dan hasil mean sesudah Mc Kenzie Exercise 27,36 dengan SD 5,569 Nilai Aktifitas Fungsional setelah dilakukan Mc Kenzie Exercise : mean 27,36 dan SD 5,569.

c. Hasil mean sebelum, 33,14 dengan SD 5,776 sedangkan hasil mean sesudah 25,71 dengan SD 6,354.

d. Nilai Selisih MKE $P=0,0118$ dan selisih CSE $P=0,241$. Dimana, bila nilai $P>0,05$ maka data berdistribusi normal

e. Nilai Aktifitas Fungsional setelah dilakukan Core Stability Exercise: mean 25,71 dan SD 6,354.

f. Hasil Uji statistik didapatkan nilai $p$ $=0,000 \leq a=0,05$ maka dapat disimpulkan bahwa terdapat Pengaruh $m c$ kenzie exercise terhadap peningkatan aktivitas fungsional pada pasien nyeri punggung bawah mekanik di rumah sakit Grandmed

g. Hasil uji statistic dapat disimpulkan bahwa terdapat Pengaruh core stability exercise terhadap peningkatan aktivitas fungsional pada pasien nyeri punggung bawah mekanik di rumah sakit Grandmed

h. Hasil uji statistic diperoleh $p$-value $\alpha<(0,000<0,05)$ maka dapat disimpulkan yaitu : "Ada Perbedaan Pemberian Mc kenzie Exercise terhadap Peningkatan Aktivitas Fungsional pada Pasien Nyeri Punggung Bawah di Rumah Sakit Grandmed

\section{DAFTAR PUSTAKA}

Brandon dan Rapel. (2013). Core stability and core stability program. Availabel from

http://sportinjurybulletin.com/archi ve/core-stability.html. Diakses pada tanggal 26 Januari 2018

Hills. E.C. (2016). Mechanical low back pain. Available from: http://www.emedicine.com. Diakses pada tanggal 27 Januari 2018.

Kisner. C. (2014). Therapeutic Exercise Foundation and Techniques. Sixth edition. Philadelphia: F.A Davis Company.

Mahadewa. T. G. B., \& Maliawan, S. (2014). Diagnosis dan Tatalaksana Kegawatdaruratan Tulang Belakang. Cetakan Pertama. Sagung Seto. Jakarta .

McKenzie. R. dan Craig Kubey. (2011). Steps To A Pain-Free Life. New York: Dutton Book Published by Penguin Group

Meliala. L dan Pinzon. R. 2014. Patofisiologi dan Penatalaksanaan Nyeri Pinggang Bawah. Dalam: Meliala L, Rusdi I, Gofir A, editor. Pain Symposium: Towards Mechanim Based Treatment, Jogjakarta.

Meliawan S. (2013). Diagnosis dan Tatalaksana HNP Lumbal. Dalam : Diagnosis dan Tatalaksana 
Jurnal Keperawatan \& Fisioterapi (JKF)

Vol. 1 No.1 Edisi Mei-Oktober 2018

http://ejournal.medistra.ac.id/index.php/JKF

Received: 02 Agustus 2018 :: Revised: 08 September 2018:: Accepted: 10 Oktober 2018

Kegawat Daruratan Tulang

Belakang. Jakarta. Sagung Seto.

Perdani P. Husni A. (2014). Pengaruh

Postur Tubuh dan Posisi Tubuh

Terhadap Timbulnya Nyeri

Punggung Bawah. Artikel Karya

Tulis Ilmiah. Universitas

Diponegoro

Quinn. Elizabeth. (2013). It's More Than Just Abs It's More Than Just Abs. Available from: http://sportsmedicine.about.com/o d/abdominalcorestrength $1 / \mathrm{a} / \mathrm{NewC}$ ore.html.Diakses pada tanggal 17 Januari 2018

Tiger. White. Lapkas Low Back Pain rehab medik unsrat. (2013). Available from: http:// www.whitetigermtc76.c0.cc, Diakse s pada tanggal 12 Januari 2018. 